\title{
Information system governance using the cobit 5 At sari mulia hospital
}

\author{
Mambang \\ STIKES Sari Mulia Banjarmasin, Kalimantan Selatan Indonesia \\ mmbg1283@gmail.com
}

\begin{abstract}
:
Objective : Information sistem has been important elements in an organisation but getting higher information technology implementation cost requires any company or organization to implement an effective operation of information technology. Information technology was expected to help organization in achieveing their business goals and providing not only financial profit but also nonfinancial profit. To achieve their business goals and ensuring process of information technology works effectively and efficiently, a continuously audit and evaluation of our IT process need to introduced in organization. It will help organization aligning their business process with IT process. One of IT governance framework is COBIT 5. COBIT 5 is a comprehensive framewok that helps organizations to create optimal value from IT by maintaining a balance between realizing benefits and optimizing risk levels and resources use. COBIT 5 enables information and related technology to be governed and managed in a holistic manner for the whole organizations, taking full end to end business and functional area of responsibility, considering the IT-related intererst of internal and external stakeholders.
\end{abstract}

Keywords : information system, governance, COBIT 5,Sari Mulia.

\section{INTRODUCTION}

Information technology investment in a company driven by the importance of the information needed by a company. Such information can not be separated from the business aspects of a company. It encourages companies to maximize the use ofinformation technology so that investment in IT is not in vain.Company'll attempt to increase the value of IT investments has been spent on the field. The board of directors of the company has also understood the importance of a controlled IT environment, effective, and efficient. Information Systems (SI) is a combination of information technology and the activities of people using the technology to support operations and management. In a very broad sense, the term often used information system refers to the interaction between people, algorithmic processes, data, and technology. Successful utilization Information systems conducted by many companies in support of business processes have inspired the leaders of universities in applying the process of information technology which is effective by improving competitive ability and transforming services, work processes and relationships among communities of academics, researchers and various levels of interests and stakeholders. 
Therefore, IT implementation needs to be carefully prepared through the governance policy (IT Governance). This is done to enhance IT's role in achieving performance, improving organizational assets, transforming services, markets, work processes, relationships business and enhance the organization's competitive advantage.

Sari Mulia Hospital is a service institution in the field of health professional workforce in the field of health. In running the process Sari Mulia Hospital utilizing information technology in achieving its goals. But the utilization of information technology is still not managed properly, alignment in the process of information technology and business processes that have not been evaluated. It therefore requires an audit or evaluation to ensure that stakeholder needs, conditions and preferences are in line with the organization's objectives of defining priorities in decision-making, and monitoring performance on purpose and direction. Expected with the audit and evaluation related to the process of technology governance COBIT (Control Objective for Information and related Technology). COBIT is a framework or guidance of best practices management and information technology. The COBIT template used is COBIT 5 which is the most recent COBIT template. The advantages of COBIT 5 are that they have identified some of the challenges facing the COBIT Maturity Model and offer an alternative research model. They have demonstrated that the alternative model of assessment based on ISO / IEC 15504 is COBIT 5 has more accurate, consistent, and objective research criteria. Therefore they stated that the research model based on ISO 15504 is more superior which is better known as Model Capability Level in COBIT 4.1. [11] Information system, governance, COBIT 5,Sari Mulia

\section{RELATED WORK}

\section{A. IT Governance}

Information Technology Governance is defined as activity establishes decisionmaking rights and accountability framework. Information Technology Governance encompasses the cultures, organizers, regulations and practices that result in a system of oversight and transparency in the utilization of IT. Information Technology Governance is part of a larger corporate but corporate activity with its own focus. Advantages in the application of IT risk management is good, monitoring and reducing the burden of failure from the implementation of IT but can also generate trust, cohesiveness, and confidence in the use of IT resources and also for IT services. [9]

\section{Information Technology Governance} explains who made the decision and how the decision was made (in IT). Information Technology Governance is a process by which organizations align IT actions with the vision and mission the organization seeks to achieve. This is achieved by making the right decision (who decides what) and 
implementing an accountability framework (who is responsible for what) so that every decision taken can develop the use of IT in the organization. [4]

There are some research about IT governance framework. Many standard are used to be the reference of planning IT governance framework, such as ITIL, Val IT, COBIT, etc. Belgian Financial [4] has been performed IT governance framework based on ITIL by separating IT department and other and the result of implementation has been discussed. Val IT is also standard that has been discussed in some paper.[8] discuss about investment of IT in commercial bank in Indonesia based on Val IT and have to work hard to optimize the IT investment. The analysis of Val IT framework implementation has been done in [11]. The result is Isfahan can increase IT investment by performing Val IT framework.Research in [13] has been done to analyse the correlation of governance maturity level and enterprise productivity based on COBIT 4.1. The result is there are no correlation between governance maturity level and prouctivity level.

\section{B. COBIT 5}

On COBIT 5 which is the latest framework which was released COBIT in 2012 which features some additional features. In COBIT 5 is equipped by 5 principles and 7 enablers are given to complement the features that previously existed in previous versions of COBIT 4.1. At COBIT introduced IT VAL elements, Val IT is a governance framework that includes the acceptance principles of supporting processes related to evaluation and selection that enable IT investments in business, realizing the benefits, and generating value from those investments. There is also a clear separation between the governance process and the management processes contained in COBIT 5. So it can be concluded COBIT 5 is built on the development of COBIT 4.1 by integrating Val IT and IT Risk from ISACA, ITIL, and relevant standards from ISO. [7, 8]

According to COBIT, good business decisions should be based on knowledge derived from relevant, comprehensive and timely information, which can be generated if information meets the information criteria. The COBIT Framework 5, which consists of 5 main principles and is equipped with 7 enablers. COBIT 5 synchronizes five principles that enable enterprise organizations to build an effective governance and management framework based on the holistic approach of the seven enablers provided to optimize the investment in technology and information while providing benefits to stakeholders. In Figure 1 we can see the five principles of COBIT 5. [1, 2, 4]

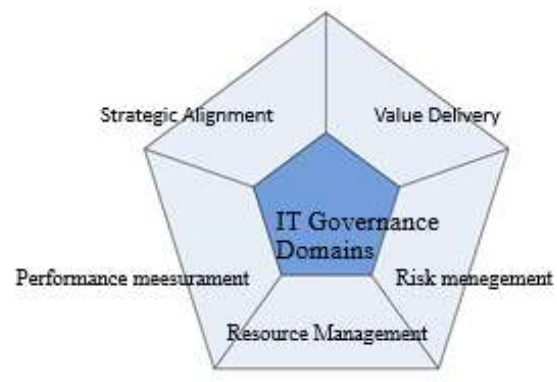

Figure 1. IT Governance Area Focus 
In Figure 2 we can see the seven enablers present in COBIT 5.

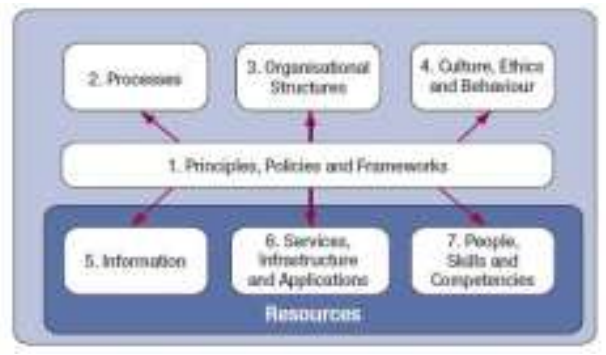

Figure 2 Seven COBIT enblers 5

In order to understand the COBIT 5 framework it is important to know what are the driving factors in COBIT 5 what are the processes contained therein and how the assessment indicators of the process assessments model in COBIT 5. The information technology activities in COBIT 5 are defined as the two main business dimensions of governance and management. [7] [8]

a. Governance - Consists of five domains in the evaluate, direct, and monitor (EDM) process.

b. Management - Consisting of 4 major domains that are responsible for Plan, Build, Run, and Monitor (PBRM) areas. The domains in the COBIT 5 management area are a development of a previous version with developments that can cover a larger area. It can be concluded that COBIT 5 has 2 main work areas separated between management and governance. There are 5 main domains in 2 COBIT 5 work areas:

Governance of Enterprise IT

Evaluate, Direct and Monitor (EDM)
Management of Enterprise IT

Align, Plan, and Organise (APO)

Build, Acquire, and Implement (BAI)

Deliver, Service, and Support (DSS)

Monitor,Evaluate, and Assess (MEA)

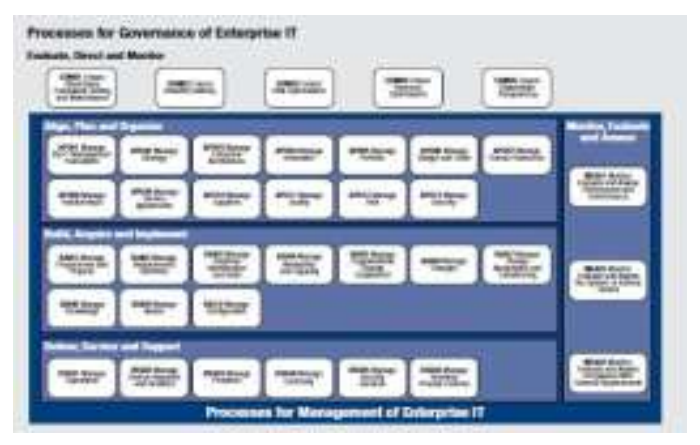

Figure 3 the main areas of management and governance in cobit 5

C. Capability Level Process

Understanding of the status of information technology systems, it is necessary for the organization, in order to decide the level of management and control that must be provided, therefore the company needs to know what to measure and how the measurement is done, so that the status level of performance is required. In the previous version of COBIT we know of the Maturity level but on COBIT 5 we are familiar with the name of Capability level. This measurement model is based on the standard ISO / IEC 15504 Software Engineering-Process Assessment Standard. There are 6 levels of level process that must be achieved in each process, the following is the 6 Capability level found in COBIT 5 [5] [8]:

a. Level 0 (Incomplete), not implemented or little / no systematic evidence of the purpose of the process. 
b. Level 1 (Performed), has achieved the purpose of the process.

c. Level 2 (Managed), implemented in a managed model (planned, monitored and customized) with appropriate, controlled, and maintained product work.

d. Level 3 (Established), implemented according to existing standards.

e. Level 4 (Predictable), operates within specified limits to achieve process results.

f. Level 5 (Optimized), continuously upgraded to meet the latest relevant and geared to business goals.

\section{METHOD}

This study aims to identify how the process of SI that took place in RS.Sari Mulia whether already running and managed well and also identification of expected conditions in the future. Identification of ongoing IT processes is done by observation, interviews, questionnaires, and field studies. While the identification of expected conditions in the future is done by interviewing to the policy makers in RS.Sari Mulia organization.

The data already obtained will be mapped into Enterprises Goal and IT-related Goals COBIT 5 to be obtained whichever process becomes the focus in RS.Sari Mulia for evaluation and enhanced performance. The process represents a process that is appropriate to the work culture of the SI unit in RS.Sari Mulia with improved performance in the process is expected RS.Sari Mulia can be easier to achieve business objectives by supporting IT efficiently and effectively.

Figure 4 shows the flowchart of this research stage:

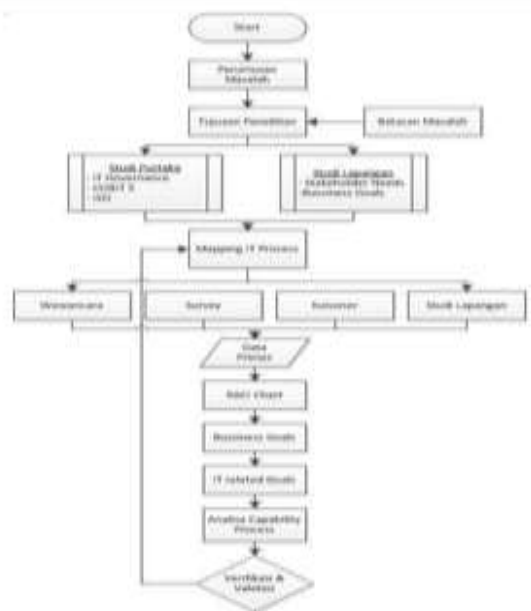

$\frac{t}{\frac{1}{4}}$

Oambar. 4 Flowehart Denelitian

Table 1 shows the mapping of the RS.Sari Mulia strategic plan to Enterprise Goals

Table 1 Mapping to Enterprise Goals

\begin{tabular}{|c|c|c|c|c|c|c|}
\hline \multirow{2}{*}{ Kode } & \multicolumn{7}{|c|}{ Btrategi } \\
\hline & & & & & & \\
& R1 & R2 & R3 & R4 & R5 & R6 \\
\hline EG01 & $\sqrt{ }$ & $\sqrt{ }$ & $\sqrt{ }$ & $\sqrt{ }$ & $\sqrt{ }$ & $\sqrt{ }$ \\
\hline EG02 & $\sqrt{ }$ & & $\sqrt{ }$ & $\sqrt{ }$ & & $\sqrt{ }$ \\
\hline EG03 & & $\sqrt{ }$ & $\sqrt{ }$ & & & \\
\hline EG04 & & & & $\sqrt{ }$ & $\sqrt{ }$ & \\
\hline EG05 & & & & $\sqrt{ }$ & $\sqrt{ }$ \\
\hline EG06 & $\sqrt{ }$ & $\sqrt{ }$ & $\sqrt{ }$ & & $\sqrt{ }$ & \\
\hline EG07 & & $\sqrt{ }$ & $\sqrt{ }$ & & \\
\hline EG08 & $\sqrt{ }$ & $\sqrt{ }$ & $\sqrt{ }$ & & & \\
\hline EG09 & & $\sqrt{ }$ & & & $\sqrt{ }$ & \\
\hline EG10 & & & & $\sqrt{ }$ & $\sqrt{ }$ \\
\hline EG11 & $\sqrt{ }$ & & & & $\sqrt{ }$ \\
\hline
\end{tabular}




\begin{tabular}{|c|c|c|c|c|c|c|} 
EG12 & & & $\sqrt{ }$ & $\sqrt{ }$ & & \\
\hline EG13 & & & & $\sqrt{ }$ & $\sqrt{ }$ & \\
\hline EG14 & $\sqrt{ }$ & $\sqrt{ }$ & $\sqrt{ }$ & & $\sqrt{ }$ & \\
\hline EG15 & & & & $\sqrt{ }$ & $\sqrt{ }$ & \\
\hline EG16 & $\sqrt{ }$ & $\sqrt{ }$ & & & & $\sqrt{ }$ \\
\hline EG17 & $\sqrt{ }$ & $\sqrt{ }$ & & & & $\sqrt{ }$ \\
\hline
\end{tabular}

From the mapping results are taken 8 points Enterprise goals are EG 01, EG 02, EG 06, EG 08, EG 11, EG 14, EG 16, and EG 17 which will be brought on the IT-related Goals mapping.

Table 2 shows the mapping from Enterprise Goals to IT related Goals.

Tabel 2 Mapping IT related Goals

\begin{tabular}{|c|c|c|c|c|c|c|c|c|}
\hline \multirow[b]{2}{*}{$\begin{array}{c}\text { Kode } \\
\text { ITr }\end{array}$} & \multicolumn{8}{|c|}{$\begin{array}{l}\text { Enterprise } \\
\text { Goals }\end{array}$} \\
\hline & $\bar{\theta}$ & $\stackrel{\jmath}{\sigma}$ & s & $\infty$ & $=$ & $\Xi$ & $\underline{-}$ & 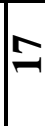 \\
\hline ITr01 & $\bar{P}$ & $\bar{P}$ & $\mathrm{P}$ & $\bar{P}$ & & & & \\
\hline ITr02 & & & & & & & & \\
\hline ITr03 & $P$ & & & & & & & \\
\hline ITr04 & & & & & & & & \\
\hline ITr05 & $\mathrm{P}$ & $P$ & & & & & & \\
\hline ITr06 & & & & & & & & \\
\hline ITr07 & $\bar{P}$ & $\bar{P}$ & $\bar{P}$ & $\bar{P}$ & $\mathrm{P}$ & & & \\
\hline ITr08 & & & & & $P$ & $\mathrm{P}$ & & \\
\hline ITr09 & & $\bar{P}$ & & $\bar{P}$ & $\bar{P}$ & & & $P$ \\
\hline ITr10 & & & & & & & & \\
\hline ITr11 & $\mathrm{P}$ & & & & & & & \\
\hline ITr12 & & $\bar{P}$ & & & $\bar{P}$ & & & \\
\hline ITr13 & $\mathrm{P}$ & & & & & & & \\
\hline ITr14 & & & & & & & & \\
\hline
\end{tabular}

\begin{tabular}{|l|l|l|l|l|l|l|l|l|} 
ITr15 & & & & & & & & \\
\hline ITr16 & & & & & & $\mathrm{P}$ & $\mathrm{P}$ & \\
\hline ITr17 & & $\mathrm{P}$ & & $\mathrm{P}$ & & & & \\
\hline
\end{tabular}

From the mapping results were taken 11 IT related Goals points that got the most primary points were ITr 01, ITr 03, ITr 05, ITr 07, ITr 08, ITr 09, ITr 11, ITr 12, ITr 13, ITr 16, and ITr 17 which will brought on the IT processs mapping.

Table 3 shows a mapping of IT related Goals to the IT process. The value of $\mathrm{P}$ meurupakan Primary points are considered important and the value of S represents the Secondary value is considered as a support point.

Tabel 3 Pemetaan menuju IT related Goals

\begin{tabular}{|c|c|c|c|}
\hline $\begin{array}{l}\text { IT code } \\
\text { Process }\end{array}$ & \begin{tabular}{|c|} 
value \\
$\mathbf{P}$
\end{tabular} & $\begin{array}{c}\text { value } \\
\mathrm{S}\end{array}$ & $\begin{array}{c}\text { identification } \\
\text { value }\end{array}$ \\
\hline EDM 01 & 3 & 7 & $P$ \\
\hline EDM 02 & 4 & 6 & $\bar{P}$ \\
\hline EDM 04 & 3 & 7 & $\mathrm{P}$ \\
\hline APO 01 & 5 & 4 & $\mathrm{P}$ \\
\hline APO 02 & 3 & 8 & $\mathrm{P}$ \\
\hline APO 03 & 3 & 6 & $P$ \\
\hline APO 04 & 5 & 1 & $\bar{P}$ \\
\hline APO 05 & 3 & 6 & $\mathrm{P}$ \\
\hline APO 07 & 5 & 3 & $\bar{P}$ \\
\hline APO 08 & 4 & 6 & $\mathrm{P}$ \\
\hline APO 10 & 2 & 5 & $P$ \\
\hline APO 11 & 3 & 6 & $\mathrm{P}$ \\
\hline BAI 01 & 3 & 5 & $\bar{P}$ \\
\hline BAI 02 & 3 & 7 & $\mathrm{P}$ \\
\hline BAI 03 & 1 & 7 & $P$ \\
\hline BAI 04 & 2 & 5 & $\mathrm{P}$ \\
\hline
\end{tabular}




\begin{tabular}{|c|c|c|c|} 
BAI 05 & 3 & 7 & $\mathrm{P}$ \\
\hline BAI 07 & 2 & 5 & $\mathrm{P}$ \\
\hline BAI 08 & 2 & 6 & $\mathrm{P}$ \\
\hline DSS 01 & 2 & 5 & $\mathrm{P}$ \\
\hline
\end{tabular}

From the mapping results, 20 processes were taken from 37 processes in COBIT 5 to assess the capability level in each process. [6]

\section{DISCUSSION}

\section{A. Analysis}

This stage is the stage of value calculation capability of each process. Capability assessment is based on the assessment standards that are in the COBIT 5 assessment model.

Capability level assessment is divided into 6 levels and 4 criteria at each level. Each process is assessed whether the activities representing each process are well under way and achieving the desired objectives. The following is an example of capability probability in EDM 01 process (Ensure Governance Framework and Setting Maintenance) shown in table 4 [6]:

\section{B. Recommendations}

Recommendations delivered are divided into each level because the criteria of achieving each level vary. The RS.Sari Mulia Hospital is expected to fulfill

first requirement at level 1 that gets $\mathrm{F}$ value (Fully Achieved) at all activity in every new process continued in make improvement to reach level 2 and level 3. Here are some recommendation points to overcome gap capability level at level 1 at RS.Sari Mulia Banjarmasin:

a. Making IT-related decision-making model, this decision-making model is very important to know the individuals responsible for every project implementation. And obtained a transparency in decision-making no important decisions made unilaterally.

b. Implemented the gate review approach. This stage gate review is a process that can evaluate and assess compliance in IT governance and at the same time provide guidance on the factors of itis to the investments already made whether the investment is approved and meet the requirements.

c. Documentation of good resource allocation. The allocation of resources (IT, technology and people) is expected to be detailed with specifications and capabilities. So it can simplify the RS.Sari Mulia party in mapping the present condition.

d. Guidelines related to data security, control, and data integrating assurance.

e. Mapping related to current IT capabilities, IT environment conditions, capabilities, and services comparable to desired conditions.

f. The creation of Enterprise Architecture with the framework has been standardized for example with the Zachman framework.

g. Evidence of innovation in follow-up by the management so that data validation occurs, and can guarantee the effectiveness of the implementation of the process. 
h. The introduction of the milestones ROI model, which can monitor the progress of portfolio implementation being assessed at each stage.

i. The grouping of human resource related inventory in the IT division, so as to differentiate the capabilities and competencies of each individual.

The following are some recommendation points for addressing the gap capability level to level 2 in RS.Sari Mulia:

\section{Performance Management Level 2}

a. Identify the objective performance of each process.

b. Planning and monitoring the performance of the process.

c. The performance of the process is tailored to the planning.

d. There is an assignment to each process implementation.

e. Provision of resources and supporting information on each process.

f. Provide discriminating communication to the parties involved.

2. Work Product Management Level 2

a. Implementation and identification of needs.

b. The presence of documentation and control.

c. Review of the harmonious work.

The following are some recommendation points for addressing the gap capability level to level 2 in RS.Sari Mulia

a. Making IT strategic plan (IT masterplan) IT division. b. Establish mechanism of capability assessment and gap analysis related to critical services and processes.

c. Improved IT investment portfolio.

d. Completion of Enterprises Architecture by utilizing existing standards while involving third parties in EA creation.

e. Creation of Human Resources System (HR System) which can mimic all human resources based on ability, competence, and experience.

f. Business and IT planning cycles and Business IT planning plans.

g. Documenting the terms of the joint venture / purchasing agreement, the supplier's risk addressing document designated into a procurement system (purchasing system).

h. Applied appropriate tender mechanism in suppliers selection.

i. Establishment and application of SDLC (System DevelopmentLife Cycle) model which become standard in implementing an application or project at RS.Sari Mulia.

\section{CONCLUSIONS}

\section{A. Conclusion}

Based on the results of analysis and evaluation of governanceinformation technology RS.Sari Mulia use framework COBIT 5, it can be concluded things as follows:

1. Based on the mapping between business objectives and RS.Sari Mulia Strategic Plan there are 20 out of 37 processes that are the main focus of the research which is divided into 4 domains. 
2. Based on the analysis of IT governance in RS.Sari Mulia obtained value capability level at level 1 (Performed Process) which states that every IT process in RS.Sari Mulia has run well and have got the goal to be achieved. While the expectation level is expected at level 2 (Managed Process) and there are 6 processes that are expected to reach level 3.

3. In order to achieve the targeted level, several recommendations are based on the work culture and standards

\section{B. Suggestions}

1. It is advisable for the researcher to process the required document identification should be discussed in more detail with the discussion with the related parties so that they can better understand the work process that runs in RS.Sari Mulia.

2. Suggested for recommendation points should be accompanied by examples related to the implementation of the already good so that the RS.Sari Mulia can know the picture in the process of improving the process that still got the value under the desire

\section{REFERENCES}

[1] Arif L. Analysis of Information Technology Governance With Framework Cobit 5 Domain Edm01 At Polytechnic of Hope Together. Thesis, Faculty of Computer Science. 2015.

[2] IT Governance Institute, Enterprise Value: Governance of IT Investment. The Val IT Framework 2.0 Extract. 2008

[3] Gondodiyoto, Sanyoto. 2007. Information System Audit + COBIT Approach. Jakarta: Media Discourse Partners.

[4] IT Governance Institute (ITGI). 2007. COBIT 4.1: Framework, Control
Objectives, Management Guidelines, Maturity Models. Rolling Meadow. USA

[5] Elvira, Marina. 2013. Designing IT Governance for Telkom University by using COBIT Tool 5. Thesis Faculty of Industrial Engineering Institut Teknologi Telkom Bandung.

[6] IT Governance Institute. COBIT 5.0. 2012. Enabling Process

[7] IT Governance Institute. COBIT 5.0. 2012. Introduction to COBIT 5.

[8] IT Governance Institute. COBIT 5.0. 2012. Main Framework Version 2.

[9] Weber, Ron. 2000. Information System Controls and Audit. New Jersey: Prentice Hall, Inc.

[10] Weill, Peter, \& Jeanne W, Ross. 2004. IT Governance: How Top Performance IT Manage Decision Rights For Superior Result. Havard School Press.

[11] Alvin, Wongso. 2013. Analysis and Evaluation of IT Governance in PT.FIF with COBIT standard 5. Thesis Department of Information Systems Binus University

[12] Lutfianto A. Analysis of Information Technology Governance with the COBIT 5 domain EDM01 framework at Polytechnic of Hope Together with Tegal. Dian Nuswantoro University. 2014. 